ejemplos. Cantar sus miserias no parece ser cosa extraña en los poetas populares. Una de las letras de la Segunda parte del Romancero de Arias Pérez (fol. 13) comienza precisamente: "Cantemos ciuilidades" (apud Gallardo, Ensayo, t. 1, col. 298). El mismo Arias Pérez, en el prólogo al lector de su Primavera y flor de los mejores romances (Sevilla, 1626), nos ofrece este otro ejemplo (apud Gallardo, ibid., 294):

Ya me parece, lector escrupuloso, que te armas de murmuraciones contra este primer ahijado de mis estudios y que me pones capítulos, no tanto deseoso de que te los suelte, cuanto de mostrar por ellos que sabes (si discreción a costa ajena merece nombre de sabiduría); dirás que es civilidad de espíritu valerse de estudios y querer ganar con ellos nombre.

Luis Jaime Cisneros

Instituto Riva Agüero, Lima.

\title{
GINCO DRAMAS INSPIRADOS EN LAS RIMAS DE BÉCQUER
}

Son varios los estudios que han demostrado la influencia de Bécquer en las letras españolas e hispanoamericanas ${ }^{1}$, pero ninguno, que yo sepa, ha tenido en cuenta el influjo del poeta en el campo dramático ${ }^{2}$. Como los sentimientos humanos elementales -el amor a la mujer, el anhelo de lo inalcanzable, la felicidad, el dolor, la desesperación y el desencanto- son los temas más frecuentes de las Rimas, no es de extrañar que éstas inspiraran piezas teatrales de dos dramaturgos mexicanos y de tres españoles. Es curioso, por cierto, que los mexicanos compusieran sus

1 No existe aún un estudio completo de la influencia de Bécquer, el hombre que hizo ver nuevas posibilidades en prosa y poesía a los españoles y a los hispanoamericanos. Pueden consultarse, sin embargo, los siguientes trabajos: MaX Henríquez Ureña, El retorno de los galeones, Madrid, s. a., pp. 23-27; G. A. BÉcQUer, Páginas abandonadas del olvido en el ángulo oscuro, ensayo biocrítico, apéndices y notas por Gamallo Fierros, Madrid, 1948, pp. 475-479; Charles F. Fraker, "Gustavo Adolfo Bécquer and the Modernists", $H R, 3$ (1935), 36-44; R. Anthony Castagnaro, "Bécquer and Gutiérrez Nájera", HispB, 27 (1944), 160-163; I. L. McClelland, "Bécquer, Rubén Darío and Rosalía Castro", BSS, 16 (1939) , 63-83; Pedro Henríquez Ureña, Literary currents in Hispanic America, Cambridge, Mass., 1945, p. 258; Arturo TorresRioseco, Precursores del modernismo, Madrid, 1925, pp. 104-105; del mismo, Rubén Dario: casticismo y americanismo, Cambridge, Mass., 1931, pp. 217-220; Julio A. Leguizamón, Historia de la literatura hispanoamericana, Buenos Aires, 1945, t. 1, pp. 543, 6og-610, 621, 641-642; t. 2, pp. 196, 246-247, 261, 287, 289-29o, 294, 307; ENRIQUE ANDERSON IMBERT, Historia de la literatura hispanoamericana, México, 1954, pp. 188, $192-195,203,205,208$.

2 Un estudio sobre la influencia de Bécquer en el teatro hace recordar su propia colaboración en la composición de seis zarzuelas. Bécquer escribió asimismo una piececita romántica, Un drama, y colaboró con Luis García Luna en la comedia La novia y el pantalón. Bécquer, García Luna y Julio Nombela adaptaron para la escena Notre Dame de Paris de Victor Hugo bajo el título de Esmeralda. Véase Teatro de G. A. Bécquer, ed., estudio prel., notas y apénd. de J. A. Tamayo, Madrid, 1949; E. Cotarelo, "Ensayo histórico sobre la zarzuela, o sea el drama lírico español, desde su origen a fines del siglo xix", $B A E, 22$ (1935), pp. 138, 402, 415; 23 (1936), pp. 61, 73; Paul Patrick Rogers, "Bécquer: some pseudonyms and pseudonymous plays", $H R, 7$ (1939) , 62-68, y "A note on Bécquer and Clavigo", $H R, 8$ (1940), p. 66; Julıo Nombela, Impresiones y recuerdos, Madrid, 1909, t. 2, pp. 324-332; HARVEY L. JohNson, "Bécquer's Un drama", $H R, 21$ (1953), 150-154. 
obras en el último cuarto del siglo xIx, unos años antes que los españoles, cuyos dramas fueron motivados, en dos casos, por propósitos ulteriores: reunir fondos para un monumento a la memoria de Bécquer, y conmemorar el centenario de su nacimiento.

Las rimas de Bécquer, episodio dramático en un acto y en verso, por Ramón Rodríguez Rivera, Córdoba (Veracruz), 1878 (9 pp. a dos columnas) ${ }^{3}$ tiene sólo dos personas en el reparto. La acción es casi nula. El tiempo transcurrido será una media hora. Luis regresa arrepentido y deseoso de recuperar el amor de Rosa. En el salón, lujosamente amueblado, todo despierta tiernos recuerdos de sus pasadas relaciones. $\overline{\mathrm{E}} \mathrm{I}$ joven descubre en el álbum de Rosa algunos poemas firmados por un tal Alberto, y repite estos versos que recuerdan la primera estrofa de la Rima $48(I)^{4}$ :

¡Que sé arrancarme esta pena aunque me cueste la vida!

Luego su atención se desvía hacia una colección de versos de Bécquer, y lee en voz alta la Rima 33 (69) y la Rima $4^{I}(26)$, muy a propósito para interpretar los problemas de los dos amantes. Al oír los pasos de Rosa, Luis se esconde. Ella, creyéndose sola, declara que ama a Luis, y que si lo maltrata es a causa de una supuesta ofensa que él le hizo. (Aunque Luis no es enteramente culpable, ella quiere humillar su orgullo). La mirada de la muchacha cae sobre el libro, abierto en la página donde se halla la Rima 30 (4o). La desconciertan un poco estos versos que tratan del falso orgullo, lo mismo que los de la Rima 44 (Io), que la hacen llorar y confesar su amor. Aún indecisa, la joven lee después dos estrofas de la Rima $4^{8}(I)$, que de nuevo refuerzan su determinación de no ceder; Rosa se pregunta si Luis, por medio de estos mismos versos, quiere insinuar que lo olvide. La Rima 35 (78) también la perturba, aunque no puede convencerse de que Luis eligiera los versos del poema para que ella los leyera, ya que afirman que uno de los amantes nunca fué completamente apreciado. Sale la muchacha, y Luis deja su escondite. Quiere recobrar su serenidad. Se reprocha por no haber reclamado el cariño de su amada. Rosa, al aparecer por segunda vez, habla de pequeñeces y trivialidades de sociedad y, con versos que hacen eco a la Rima 56 (20), se queja de la monótona rutina de su vida. Luis intenta declararle su amor, pero las respuestas burlonas de la muchacha hieren su amor propio. La altivez, el orgullo, la vanidad y la preocupación por la vana opinión de la sociedad la hacen rechazar la oferta de matrimonio. La escena final recuerda en cierto modo la Rima 30 (40) y la 33 (69).

${ }^{3}$ La edición consultada está en: Teatro mexicano. (Colección de obras modernas en prosa y verso por diversos autores), José María Sandoval, impresor, México.

${ }_{4}$ El 48 es el número de las ediciones impresas (empleo las Obras completas, col. Paradilla del Alcor, Madrid, 1949); el I entre paréntesis es el número de la Rima en el manuscrito de Bécquer (Libro de los gorriones). Seguiré en adelante este sistema. Véase una descripción del manuscrito y un estudio de las Rimas en Franz Schneider, Gustavo Adolfo Bécquers Leben und Schaffen unter besonderer Betonung des chronologischen Elementes, Leipzig, 1914, pp. 66-67, y "Gustavo Adolfo Bécquer as poeta and his knowledge of Heine's Lieder", $M P$. 19 (1921), 245-249. 
En resumen, Rodríguez Rivera debe mucho a las Rimas de Bécquer, las cuales suministran ideas enteramente compatibles con los sentimientos de los dos personajes, insinuando todo lo inexplicable, irracional y misterioso en sus reacciones sentimentales. Si algún mérito artístico hay en la pieza, se debe al talento del autor, que supo fundir algunos versos e ideas de Bécquer dentro de cuatro escenas.

La Rima II (5I) parece haber tenido un atractivo especial para dramaturgos y para poetas ${ }^{5}$. El mexicano Antonio de Paula Moreno basó en ella El sueño del poeta, fantasía dramática en un acto y en verso, publicada en México, agosto 20 de 1893 (17 pp.) ${ }^{6}$. Aunque excelente por su concepción y rico en imágenes, es un drama mediocre; sus versos son a veces pobres y prosaicos, y su lenguaje algo retórico. Hay cuatro personajes: el idealista Gustavo, la apasionada Magdalena, la tierna Elvira y el realista Jacobo. El lugar de la acción es la finca de este último, con su río, cascadas y montañas visibles a la luz de la luna. Gustavo y Jacobo no llegan a ningún acuerdo en su discusión (p. 8):

$$
\begin{aligned}
& \text { JAC.- Si me parece imposible } \\
& \text { que en pleno positivismo } \\
& \text { exista tanto lirismo, } \\
& \text { tanto amor a lo intangible! } \\
& \text { Gus.-Déjame soñar a mí } \\
& \text { y vive en tu mundo real. }
\end{aligned}
$$

El poeta quiere encontrar en las dos mujeres que lo admiran la imagen de sus ilusiones, de sus quimeras, pero en vano, pues una distancia incalculable las separa de su ideal, "visión encantadora / de nívea vestidura". Gustavo expresa en ardientes versos, con acompañamiento de música suave, su anhelo de remontarse por encima del mundo material. Magdalena y Elvira despiertan al soñador; le dicen que vive en este mundo, y que debe aceptarlo tal como es. Luego, cada una de ellas lo tienta parafraseando las dos primeras estrofas de la Rima II (5I). En ese preciso momento aparece una figura envuelta en ropaje vaporoso, visible sólo para el poeta, el cual exclama (p. 16): “¡Angélica ...! ‘Era verdad!” Deseando tocarla, y desoyendo los ruegos de Magdalena y Elvira, el poeta avanza hasta el borde del río, desde donde cae al torrente. El espíritu atormentador se desvanece, Elvira pierde el conocimiento y Magdalena intenta arrojarse a su vez al abismo. Muy acertadamente, Moreno dió el nombre de pila de Bécquer a su protagonista.

Adaptación más artística de la Rima II $(5 I)$ es otra obra, que rivaliza con la fantasía y sutileza de Bécquer: Becqueriana, ópera en un acto, música de María Rodrigo, escrita por los hermanos Álvarez Quintero en 1913. La acción de este drama en prosa y verso ${ }^{7}$, sin división en escenas, tiene lugar en un bosque solitario a la hora del crepúsculo. Por uno

${ }^{5}$ Las tres, uno de los "poemas de adolescencia" de Rubén Darío, es en parte una elaboración de esta Rima. Véanse sus Obras poéticas completas, Madrid, 1949, pp. 57-59.

- Sobre sus otros dramas, véase Francisco MonTerde, Bibliografia del teatro en México, México, 1933, pp. 226-228.

${ }^{7}$ Citamos por la ed. de Teatro completo, t. 22, Madrid, 1927, pp. 235-248. 
de los senderos viene el Poeta quien, desilusionado del amor, anhela fundirse en el misterio de la selva. El bardo lamenta (p. 239) que la mujer de sus sueños haya permanecido siempre invisible para él ${ }^{8}$ :

El susurro de fuente escondida

para mí es tu voz;

las estrellas en el alto cielo

tus pupilas son;

el rocío que tiembla en las flores,

llanto de tu amor.

Viene entonces la Pasión, que interrumpe la melancolía del Poeta con la estrofa inicial de la Rima II (5I). Después aparece la Ternura, que recita la segunda estrofa. Las dos figuras se ofrecen al Poeta, hablando sucesivamente de los placeres que pueden brindarle. El Poeta sigue aferrado a sus fantasías. Un súbito resplandor ilumina a una tercera figura femenina, la Ilusión. El joven nunca ha visto a una mujer semejante. Hipnotizado por esta doncella etérea, ideal, el Poeta la persigue y le ruega que no huya. La Ilusión responde con la tercera estrofa de la Rima ya citada, diciendo que nunca podrá amarlo ni ser suya, y que huye para que su fantasía pueda vivir. Cuando el Poeta, frenético, trata de abrazarla, la incorpórea visión recita de nuevo unas palabras de la tercera estrofa y luego se desvanece en una llama azulada. Él retrocede, y cae sollozando sobre un tronco caído en el suelo.

Esta ópera es fuertemente simbolista. Los matices rosa y oro del cielo crepuscular corresponden a las dos primeras mujeres: la Pasión, "de hermosura de fuego", y la Ternura, de frente pálida y trenzas de oro. La Ilusión surge en el momento propicio, cuando el tibio resplandor de la luna va invadiendo el cielo ${ }^{9}$. La Pasión y la Ternura entran y salen por distintos senderos, para significar que estas dos emociones no pueden fundirse en una. El tronco en el suelo representa quizá al hombre desesperado. Becqueriana no tiene argumento ni acción. El único ser humano, el Poeta romántico - réplica del loco Manrique de El rayo de luna $a^{10}$, es el eterno soñador que no quiere renunciar a sus ilusiones y acaba donde comenzó, sentado en un tronco caído. Los demás personajes - las mujeres que personifican a las tres abstracciones de la Rima, y los seres fantásticos, como la Ninfa del bosque y los Genios y Espíritus de la tarde- no tienen realidad humana. También en las acotaciones hay alguna huella de Bécquer: las palabras: “. . estremécese el bosque todo como si el amor batiera en él sus alas poderosas” (p. 240) son paráfrasis de la Rima ro (46).

8 En sus "Pensamientos" (Obras completas, p. 1325) expresa Bécquer la misma idea: “. . he pasado los días más hermosos de mi existencia aguardando una mujer que no llega nunca..." Bécquer prefirió no conocer a Julia, a quien sólo divisó de lejos en un balcón, temiendo sufrir un desencanto (véase Nombela, op. cit., t. 2, pp. 429-430).

- El color es un elemento importantísimo de las imágenes de Bécquer; los Alvarez Quintero quieren aquí, seguramente, conservar la técnica del poeta. Véase, acerca de ésta, el detenido análisis de I. L. MCClelland, "The poetry of Bécquer: an appreciation", BSS, 12 (1935), 107-108.

10 BÉCquer, Obras completas, pp. 155-169. 
La rima eterna, también por los Állvarez Quintero ${ }^{11}$, se inspira en la Rima 4 (39), y particularmente en los versos:

podrá no haber poetas; pero siempre

habrá poesía.

La relación entre el poema de Bécquer y las situaciones del drama es muy estrecha. Los personajes e incidentes dan sustancia definida a las ideas expresadas por el poeta. Lo que con esto pierde el argumento queda más que compensado con la delicada creación de caracteres y la fantasía y belleza del lenguaje, que en ocasiones alcanza el nivel de las Rimas.

La acción transcurre en el patio del ruinoso Monasterio del Valle, en un solitario lugar de Castilla. Dos personas viven en el viejo edificio: Telmo, muchacho irremediablemente preguntón, y su abuela, la señora Ignacia, que hace las veces de guardián. En una de las celdas se aloja don Virgilio, profesor retirado, hombre de sesenta años que a menudo viene a descansar y a buscar consuelo por la pérdida de su única hija. Llegan casualmente a pasar la noche otras tres personas: don Juanín, viejo chocho e inútil; Rosaura, su sobrina, muchacha de dieciocho años, feliz por haber dejado el convento de damianas en que estuvo interna; y Ana María, acompañante de Rosaura. Leoncio, otro recién llegado al monasterio, ha ido al valle esperando volver a ver a Rosaura, a quien ha amado con pasión por más de un año, aunque apenas la ha visto fugazmente. La Ensoñadora, a quien la señora Ignacia permite quedarse en el monasterio "porque no tiene en el mundo más que el día y la noche y la caridad que acá le prestamos" (p. 201), es una encantadora muchacha de aspecto extraño e ingenuo, en cuyos ojos brilla una luz de ilusión o fantasía. Cree en brujas y espíritus, y hasta oye voces del otro mundo. Un día encontró un libro abierto y, fascinada, aprendió a leer en él. Desde entonces ha releído tanto este volumen de poemas y leyendas de Bécquer, que ahora sabe poemas enteros de memoria. El espíritu del libro la ha transformado, convirtiéndola en lo que es. El antiguo dueño del libro, en una nota, llamó "la rima eterna" a la Rima 4(39).

Rosaura, don Virgilio, Ana María y Leoncio descubren sentimientos y pensamientos que coinciden con los expresados en la Rima antes mencionada; y entonces la Ensoñadora, con la mirada fija en el espacio, recita el poema eterno. La hija de don Virgilio ha muerto hace casi tres años, sin que la ciencia supiera la causa de su muerte. Él, no obstante, la siente sin cesar a su lado. Leoncio, mientras hojea el libro de Bécquer, dedica a los ojos de Rosaura un par de versos que escribe al margen de la leyenda El rayo de luna. Cuando los dos amantes se encuentran poco después, Leoncio envía lejos a la Ensoñadora, mañosamente, con el pretexto de que vea una nueva flor, extraña y bella, que ha brotado en la Peña Vieja, el mismo lugar desolado donde ella encontró el volumen de Bécquer; el joven queda muy asombrado cuando la chica, al regresar, le

11 Teatro completo, t. 14, pp. 187-275. Los hermanos dramaturgos escribieron esta pieza con el propósito de reunir fondos para un monumento de bronce y mármol, hecho por Coullaut Valera y descubierto el 9 de diciembre de 1911, en memoria del poeta sevillano. Véase ibid., pp. 277-278, y las Obras escogidas de BÉcQuer, pról. de S. y J. Alvarez Quintero, Madrid, s. f., t. 1, pp. 5-7. 
cuenta que encontró la flor tal como él la había descrito. Ana María, unos diez años antes, había ido con su esposo al Valle a pasar su luna de miel; ahora, cada sitio despierta en ella gratos recuerdos; durante los últimos cuatro años, esta señora ha vivido sola, pues su esposo se ha marchado a América para rehacer su fortuna. El telón cae por segunda vez cuando la Ensoñadora recita la última estrofa de "la rima eterna".

La estrecha relación entre la pieza y algunos de los escritos de Bécquer se hace más evidente a medida que el argumento se desarrolla. Leoncio, como el loco Manrique de El rayo de luna ${ }^{12}$, mencionado algunas veces en la comedia, pasa el tiempo buscando a una mujer misteriosa y desconocida, de la cual se ha enamorado a primera vista. Las estrofas de la Rima 4 (39) corresponden íntimamente con las vidas de los personajes que paran en el monasterio. A los amantes, Rosaura y Leoncio, les están bien varios versos de dos estrofas:

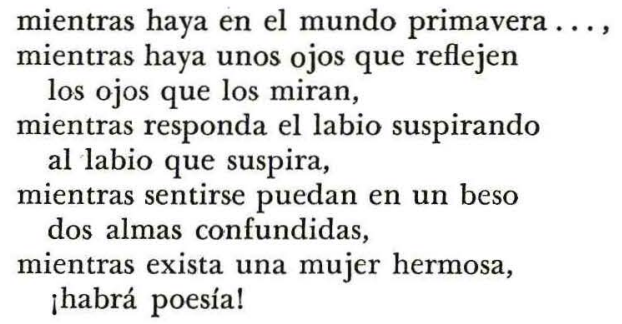

El desconsuelo de don Virgilio por la muerte enigmática de su hija encuentra adecuada expresión en estos versos:

Mientras la ciencia a descubrir no alcance
las fuentes de la vida...,
mientras haya un misterio para el hombre...

Y los sentimientos de Ana María, separada de su esposo, se traducen en el verso:

mientras haya esperanzas y recuerdos...

Leoncio, mientras habla con la Ensoñadora, lee en voz alta la primera estrofa de la Rima 16 (43), y más tarde, a solas con Rosaura, lee con ardor apasionado versos de esta misma Rima, y de la $I 7$ (50), la 24 (33) y la 25 (3I). Rosaura observa que algunas rimas hablan de las desilusiones de amor, a lo cual Leoncio responde (p. 273) con ideas de las $R i$ mas 10 (46) y 53 (38): "Nuestro amor es el que deshace el cielo en rayos de oro y estremece la tierra con el batir de sus alas invisibles. Las golondrinas que en tu balcón del Valle cuelgan esta primavera sus nidos, volverán siempre a contemplar tu hermosura y mi dicha".

La Rima ro (46) suministra también las palabras de las acotaciones que manifiestan los sentimientos de los amantes al encontrarse en la mañana del segundo día (p. 268). La Ensoñadora recita inconscientemente los dos primeros versos de la Rima 53 (38) cuando la señora Ignacia la reprocha por estar "en el claustro mirando en las bóvedas los nidos

${ }^{12}$ Los Alvarez Quintero también pueden haber tenido en cuenta la Rima 15 (6o), que es una especie de réplica lírica de El rayo de luna. 
de las golondrinas y diciendo versos como una tonta" (p. 234). Don Virgilio, después de recitar dos preguntas de la Rima 73 (7I) -el poema en que Bécquer llora la soledad de los muertos-, afirma con convicción: "Y yo pienso que cuando el dolor nos purifica, los muertos no quedan tan solos: algo de ellos vive con nosotros o algo nuestro se muere con ellos" (pp. 248-249).

Hay otros puntos de contacto, menos perceptibles, entre La rima eterna y los escritos de Bécquer. El lugar de la acción, un monasterio ruinoso y abandonado, armoniza bien con los lugares y ambientes descritos por el poeta en sus cartas Desde mi celda y en sus leyendas. Las observaciones de don Virgilio y de la señora Ignacia acerca del poder restaurador que el aire puro de las montañas tiene para el cuerpo y el alma, y las historias y leyendas relacionadas con la región del Monasterio del Valle, bien pudieran provenir de Bécquer, quien residió en el abandonado Monasterio de Veruela en 1864 para restablecer su salud. La Ensoñadora encarna muchas de las características atribuídas por el poeta a sus mujeres fantásticas y etéreas. Los huéspedes aceptan fantasía por realidad. El tono lírico y las imágenes poéticas del lenguaje son un fiel reflejo de los de Bécquer. El juego de fantasía e irrealidad de la comedia, casi desnuda de realismo - el poco que hay se debe a la señora Ignacia y a Telmo-, le dan un encanto esencialmente becqueriano.

¡Oh, dulces prendas...! , comedia en tres actos, en prosa y verso, Toledo, 1936 (75 pp.), fué escrita por Eduardo Juliá Martínez con el doble propósito de conmemorar el cuarto centenario de la muerte de Garcilaso de la Vega y el centenario del nacimiento de Bécquer. Se estrenó en el Teatro Rojas de Toledo el 23 de abril de 1936, y la representó un grupo de alumnos y ex alumnos del Instituto Nacional de Segunda Enseñanza de Toledo. De las obras que aquí hemos estudiado, este drama es el que debe menos a las Rimas. El exquisito Soneto Io de Garcilaso suministra el título y da expresión a los mismos tiernos sentimientos que el protagonista tiene por una amada muerta, pero no olvidada.

Don Lamberto, caballero de edad mediana, poeta y soldado (un "caballero Garcilaso", como se le llama), había adorado a su primera esposa y, hasta su segundo matrimonio, había concentrado todo su cariño en su hija Lucía. Ésta se muestra celosa de su madrastra Teresa, mujer poco refinada, que antes se ganaba la vida como costurera. Pero Teresa juzga desgraciado su matrimonio (afirma que se ha sacrificado para ayudar económicamente a su madre y a su hermana), y ve cada día con más rencor a don Lamberto, porque éste no le reconoce sus derechos de legítima esposa, la riñe de continuo y no deja de idolatrar a su primera mujer. Don Lamberto no se da cuenta de lo que pasa hasta que ciertas insinuaciones disimuladas le hacen sospechar de la fidelidad de Teresa. Eugenio, especie de don Juan, da pábulo a mil chismes por su asiduidad en cortejar lo mismo a Lucía que a su madrastra. Teresa trata con frialdad a su madre doña Catalina (que ha venido a visitarla), a causa del incesante interés de ésta por el bienestar de la hija menos afortunada. Doña Catalina logra convencerla de su amor maternal, y, al saber las 
causas de su infelicidad, le dice a su yerno que ambas se irán para nunca volver. Don Lamberto apenas puede creer que su esposa lo abandone, cambiando su vida de lujo por una vida de privaciones; la culpa, además, de haberlo engañado antes del matrimonio, fingiendo amor. Al final, don Lamberto se aferra a Lucía; le ruega que se quede y que olvide al indigno Eugenio, de quien la muchacha está enamorada.

El escenario se llena a veces en esta pieza, pues hay dieciocho personas en el reparto. Las escenas ligeras, y las chismografías que sirven para dar los toques humorísticos, conducen a menudo a diálogos serios y dramáticos. Se observan las unidades de acción y lugar, pero transcurren casi tres semanas entre los actos I y III. El drama termina por lo menos con dos puntos sin aclarar: I) ¿se fingió enferma Teresa con el propósito de tener una cita con Eugenio?; 2) ¿permanecerá Lucía con su padre y rechazará a Eugenio? Los poemas de Juliá Martínez, encantadores y originales, encajan admirablemente dentro de esta obra compuesta en homenaje a Garcilaso y a Bécquer. La nota de desilusión que llena la pieza armoniza también con el espíritu de esos dos poetas.

Los personajes parecen un tanto desproporcionados. El egoísta don Lamberto sufre un desencanto al querer recuperar su amor juvenil por medio de un segundo matrimonio; las insinuaciones calumniosas le hacen derramar lágrimas de celos; al final se convierte en una figura patética; no tiene valor para enfrentarse a la realidad; es ciertamente irónico que doña Catalina lo llame un “santo". En cuanto a Teresa, si obró mal al casarse por motivos egoístas, no es mala en el fondo; pero es dudosa su sinceridad cuando dice que se ha sacrificado por su familia; le parece imposible la tarea de reencarnar a otra mujer; en su resentimiento con su madre parece algo neurótica; las desilusiones y los celos la han transformado en una mujer altanera y amargada, que se complace en mortificar a los demás. Doña Catalina es, sin duda, la persona mejor de la pieza, y se gana nuestra simpatía: humilde, consciente de sus limitaciones, vive con aguda percepción una situación intolerable. Los demás personajes están adecuadamente dibujados, y coinciden con varios tipos comunes: el viejo e ingenioso misógino don Evaristo, que habla con cinismo de todo y de todos, en especial de las mujeres; doña Úrsula, vieja chocha, maligna y amiga de la murmuración, que trata de pescar un buen partido para su hija Clotilde, muchacha enferma y apática; las cuatro casquivanas que cansan con inconsideradas exigencias a su padre don Buenaventura, anciano que posee el don de decir o hacer cosas inconvenientes en momentos inoportunos; Fili, mujer parlanchina, torpe y dominadora, que, cuando charla, apenas da tiempo a su marido para exclamar: “„Por Dios, Fili!”; el alocado Pepito, que olvida sus estudios por su afición a las faldas; Lucía, retrato de su difunta madre, celosa siempre de Teresa; y finalmente el descolorido calavera Eugenio.

La presencia de Bécquer se siente desde el comienzo. Cuando se alza el telón mostrando el escenario vacío, se oye un piano tocando una melodía que es arreglo musical de la Rima 53 (38), "Volverán las oscuras golondrinas"13. En el acto II (p. 37), las muchachas quieren aprender

13 Al texto impreso del drama sigue un arreglo de esta Rima por Pedro Sosa, para voces con acompañamiento de piano. 
esa canción. Don Lamberto le habla a Teresa (p. 46) de la alegría que hizo escribir al poeta en la Rima I7 (50): "la he visto y me ha mirado"; y al intentar convencer a don Evaristo, solterón empedernido, de las ventajas del matrimonio (p. 52), cita la Rima 4 (39): "mientras exista una mujer hermosa, / ¡habrá poesía!" Teresa lee el libro de Bécquer en la tensa escena que sigue a la revelación de que ella ha dado a Eugenio la rosa favorita de Lucía (p. 54). Las cuatro hijas de don Buenaventura cantan a coro la Rima 53 (38) (p. 63) ${ }^{14}$. Don Lamberto, convencido de que todo ha terminado entre Teresa y él, recita (p. 74) la primera estrofa de la Rima $4 I$ (26), que, con su "no pudo ser", armoniza perfectamente con la situación. Por último, cuando cae el telón, vuelve a oírse (p. 75), flotando en el aire, la versión coral de "Volverán las oscuras golondrinas".

Para terminar, quisiera mencionar dos recientes producciones cinematográficas sobre la vida de Bécquer. La biografía novelada $E l$ gran amor de Gustavo Adolfo Bécquer: Una vida pobre y apasionada, por María Teresa León, proporcionó el argumento para la película argentina del mismo título. El libro y su versión cinematográfica mezclan becquerianamente fantasía y realidad, y exageran el interés de Bécquer por Julia Espín, convirtiéndolo en pasión avasalladora. Alberto de $\mathrm{Za}$ valía dirigió esta película, en la cual actúan Delia Garcés como Julia y Esteban Serrador como Bécquer ${ }^{15}$. El huésped de las tinieblas, producida por la compañía Sagitario Films, se estrenó en Madrid el 20 de septiembre de 1948, y tiene como actores principales a Carlos Muñoz y a Pastora Peña. El argumento, casi enteramente ficticio, gira en torno al idílico amor de Gustavo y Dora, que al final termina con la muerte de los dos jóvenes y su entierro uno al lado del otro.

Indiana University.

Harvey L. Johnson

\section{UN EPISODIO DE TIRANO BANDERAS}

Conocida es la costumbre de Valle-Inclán de incorporar a sus propias obras elementos textuales o reelaborados de obras ajenas. Ya hemos estudiado (NRFH, 7, 1953, 536-550) lo que Valle-Inclán debe, en Tirano Banderas, a dos crónicas que relatan las aventuras y la muerte de Lope de Aguirre. Siempre relacionado con la Novela de Tierra Caliente hemos encontrado otro aprovechamiento. El autor de que Valle se ha servido esta vez es Gerardo Murillo, conocido con el pseudónimo de "Dr. Atl"1, y la obra de cuyos elementos se vale es el cuento $L a$ iuida ${ }^{2}$. Transcribi-

14 Poco antes, durante el ensayo (p. 59), comenta irónicamente doña Úrsula: "Estamos ya de golondrinas... que no van a volver de verdad por no oír ese coro".

${ }^{15}$ La biografía de la señorita León está ilustrada con fotografías tomadas de algunas escenas de la película.

1 Escritor, pintor y crítico de arte, nacido en Jalisco en 1875 . Las obras que nos interesan en conexión con el presente trabajo son: Serie de discursos politicos (1914-1916) y Cuentos de todos los colores, tomo 1.

${ }^{2}$ Esta narración está incluída en el tomo primero de Cuentos de todos los colores, 